\title{
BMJ Open Impacts of the Regional Greenhouse Gas Initiative (RGGI) on infant mortality: a quasi-experimental study in the USA, 2003-2014
}

To cite: Lee J, Park T. Impacts of the Regional Greenhouse Gas Initiative (RGGl) on infant mortality: a quasiexperimental study in the USA, 2003-2014. BMJ Open 2019:9:e024735. doi:10.1136/ bmjopen-2018-024735

- Prepublication history and additional material for this paper are available online. To view these files, please visit the journal online (http://dx.doi. org/10.1136/bmjopen-2018024735).

Received 11 June 2018 Revised 14 January 2019 Accepted 4 March 2019

\section{Check for updates}

\section{(c) Author(s) (or their} employer(s)) 2019. Re-use permitted under CC BY-NC. No commercial re-use. See rights and permissions. Published by BMJ.

${ }^{1}$ Energy Institute, Seoul Energy Corporation, Seoul, The Republic of Korea

${ }^{2}$ Pharmacy Administration, Center for Outcomes Research and Education, St Louis College of Pharmacy, St Louis, Missouri, USA

Correspondence to Dr Taehwan Park; Taehwan.Park@stlcop.edu

\section{ABSTRACT}

Objectives The Regional Greenhouse Gas Initiative (RGGI) is the first mandatory market-based regulatory programme to limit regional carbon dioxide $\left(\mathrm{CO}_{2}\right)$ emissions in the USA Empirical evidence has shown that high concentrations of ambient air pollutants such as $\mathrm{CO}_{2}$ have been positively associated with an increased risk of morbidity (eg, respiratory conditions including asthma and lung cancer) and premature mortality. The purpose of this study was to examine the impacts of RGGl on death rates in infancy. Design A quasi-experimental difference-in-differences design.

Setting and participants We estimated the impacts of RGGI on infant mortality from 2003 through 2014 in the USA ( 6 years before and after RGGI implementation). Our analytic models included state- and year-fixed effects in addition to a number of covariates.

Outcome measures Death rates in infancy: neonatal mortality rates (NMRs), deaths under 28 days as well as infant mortality rates (IMRs), deaths under 1 year. Results Implementation of RGGl was associated with significant decreases in overall NMRs (a reduction of $0.41 / 1000$ live births) and male NMRs (a reduction of $0.43 / 1000$ live births). However, RGGI did not have a significant effect on female NMRs. Similarly, overall IMRs and male IMRs decreased significantly by $0.37 / 1000$ live births and 0.61/1000 live births, respectively, after implementation of RGGI while female IMRs were not significantly affected by RGGI.

Conclusions RGGl was associated with decreases in overall infant mortality and boy mortality through reducing air pollutant concentrations. Of note, the impact of this environmental policy on infant girls was much smaller.

\section{INTRODUCTION}

The Regional Greenhouse Gas Initiative (RGGI) is the first mandatory cap-and-trade programme designed to reduce greenhouse gas (GHG) emissions in the USA. Cap-andtrade refers to creating a limit or 'cap' on GHG emissions from various emission sources. The RGGI programme limits carbon dioxide $\left(\mathrm{CO}_{2}\right)$ emissions in particular from the electric power sector, the largest source of $\mathrm{CO}_{2}$ emissions for more than 40 years in

\section{Strengths and limitations of this study}

- This is the first study that examined the effects of the Regional Greenhouse Gas Initiative (RGGI) on infant death rates by sex.

- We investigated how the implementation of RGGI affected mortality outcomes such as neonatal mortality rates and infant mortality rates from 2003 through 2014 using a quasi-experimental difference-in-differences (DID) design.

- We included state- and year-fixed effects as well as a number of covariates in our analytic models.

- An assumption of the DID approach should be met to produce reliable results.

- Because infant deaths in this study were all-cause mortality, our analyses were not granular enough to capture the reasons for deaths.

the USA. The RGGI programme is often referred to as a market-based $\mathrm{CO}_{2}$ emission reduction programme because, under this programme, the marketplace determines the economically efficient solution for GHG emission reduction. The RGGI programme became effective in January 2009 in 10 northeastern states. New Jersey originally participated in this programme in 2009, but withdrew in 2011. Accordingly, electric power plants with 25 or more megawatts capacity in the remaining nine states continue to participate in the RGGI programme. These nine states are Connecticut, Delaware, Maine, Maryland, Massachusetts, New Hampshire, New York, Rhode Island and Vermont. The RGGI programme consists of four compliance periods, each of which lasts for 3 years (ie, 2009-2011, 2012-2014, 2015-2017 and 2018-2020). During the first 3-year compliance period (2009-2011), the emission cap was 188 million short tons of $\mathrm{CO}_{2}\left(\mathrm{mtCO}_{2}\right)$ per year, which was decreased to $165 \mathrm{mtCO}_{2}$ during the next period (2012-2013). The RGGI states then substantially reduced the emission cap from $165 \mathrm{mtCO}_{2}$ to $91 \mathrm{mtCO}_{2}$ 
in 2014. This cap has then gradually decreased by $2.5 \%$ each year from 2015 until 2020. As expected, $\mathrm{CO}_{2}$ emissions have fallen considerably in these nine states since its implementation in 2009. ${ }^{1-4}$

Prior studies have consistently shown an association between high concentrations of ambient air pollutants and an increased risk of morbidity and premature mortality. For example, extensive evidence has shown that ambient air pollutants were positively associated with asthma, lung cancer, respiratory mortality, cardiovascular mortality and total mortality. ${ }^{5-8}$

Some studies examined the impact of air pollution particularly on infant mortality ${ }^{9-11}$; however, the findings from these studies are inconsistent. One study found that regulations to reduce air pollution led to modest but statistically insignificant improvement in infant mortality in India ${ }^{9}$ whereas other studies showed that infant mortality was significantly lowered following environmental regulations in Germany and China. ${ }^{10} 11$ The variations in the findings across studies might be driven by the different strengths of the relationships between air pollution and infant mortality among the countries.

In the USA, some studies have shown that reductions in air pollution significantly decreased infant mortality. ${ }^{12-14}$ These studies evaluated infant mortality in the 1990s or earlier. Recent US-based studies regarding infant mortality have focused largely on its association with factors other than air pollution such as infants' demographics, ${ }^{15-17}$ state-level minimum wage laws ${ }^{18}$ and Medicaid expansion. ${ }^{19}$ The objective of this study was to investigate the impact of the environmental policy, RGGI, on infant mortality in recent years in the USA. Because some studies suggested that the effects of air pollution on health outcomes may be sex-specific, ${ }^{20-22}$ we examined its impact also by sex.

\section{METHODS}

\section{Infant mortality and RGGI}

The main dependent variables are two state-level death rates in infancy: the neonatal mortality rate (NMR, deaths under 28 days) and infant mortality rate (IMR, deaths under 1 year) from 2003 through 2014 (6 years, respectively, before and after RGGI implementation in 2009). We obtained the annual NMRs and IMRs from the National Vital Statistics System for this time period. ${ }^{23}$ The US states were categorised by whether they implemented the RGGI programme (RGGI states) or not (non-RGGI states).

\section{Covariates}

We included a number of state-level covariates in our analyses to control for potential confounders. To adjust for economic performance, population size and household financial status of the included states, we obtained total gross domestic product (GDP), residential population and the median household income data from the Federal Reserve Bank (Federal Reserve Economic Data ${ }^{24}$ ) to include them as covariates in our model. To control for the characteristics of infants and mothers, we included total number of births, birth weight, birth rate of black babies and mother's education level (ie, rate of high school graduate or higher), all of which were obtained from the Centres for Disease Control and Prevention Wide-ranging ONline Data for Epidemiologic Research (CDC WONDER) database. ${ }^{25}$ Furthermore, using data from the HenryJ. Kaiser Family Foundation, ${ }^{26}$ we included the number of hospitals in each state. Finally, we included the average temperatures of each state obtained from the National Oceanic and Atmospheric Administration. ${ }^{27}$

However, mothers' education data were not available in some states. Accordingly, we excluded these states in our analysis: one RGGI state (Connecticut) and three non-RGGI states (Arizona, Illinois and Tennessee). New Jersey was also excluded from the RGGI states because this state withdrew from the RGGI program in 2011; thus, our analysis included 46 states. Of these 46 states, eight states (Delaware, Maine, Maryland, Massachusetts, New Hampshire, New York, Rhode Island and Vermont) were categorised as RGGI states.

\section{Statistical analysis}

We investigated the impacts of RGGI on mortality outcomes by using a quasi-experimental difference-in-differences (DID) approach. The DID method is a useful tool to evaluate treatment effects by comparing the pre- and post-treatment differences in an outcome between a treatment group and a control group. This analytic method relies on the assumption that in the absence of the treatment, the average outcome for a treatment group would follow similar trends over time as the average outcome for a control group. Therefore, the treatment effect is estimated by comparing the average change in the outcome over time for the treatment group with the average change over time for the control group. In this study, we compared changes in mortality outcomes among RGGI states (treatment group) with those among non-RGGI states (control group) after the implementation of RGGI to assess how this implementation affected mortality outcomes such as NMRs and IMRs. To compare mortality changes over time, we used a multivariate regression model by controlling for a number of covariates such as GDP, residential population total number of births, birth weight, birth rate of black babies, mother's education level and number of hospitals. A full set of year- and state-fixed effects were also included in our model to control for unobservable time invariant and state-specific effects. An interaction term between RGGI status and time in our model captures the impacts of RGGI on mortality outcomes. Mortality outcomes were also examined by sex.

Thus, the DID model in this study is specified as follows: $\mathrm{Y}_{\mathrm{it}}=\alpha+\beta_{1}(\mathrm{PD} * \mathrm{TD})+\beta_{2} \mathrm{X}_{\mathrm{it}}+\gamma_{\mathrm{i}}+\delta_{\mathrm{t}}+\varepsilon_{\mathrm{it}}$

where $Y_{i t}$ is death rate in infancy in state $i$ in year $t, P D$ is a policy dummy variable that takes one for RGGI states and zero for non-RGGI states, TD is a time dummy variable that equals one for years 2009 or later and zero for years 2008 or earlier, $\mathrm{X}_{\mathrm{it}}$ indicates control variables, $\gamma_{\mathrm{i}}$ is state fixed effect and $\delta_{\mathrm{t}}$ is time fixed effect. The coefficient $\beta_{1}$ 
Table 1 Characteristics of Regional Greenhouse Gas Initiative (RGGI) states versus non-RGGI states in the USA, 2003-2014

\begin{tabular}{|c|c|c|c|c|}
\hline & All states & RGGI states & Non-RGGI states & P value* \\
\hline GDP (Millions of US\$), mean \pm SD & $275019 \pm 363987$ & $259637 \pm 365497$ & $278087 \pm 362357$ & 0.6509 \\
\hline Population (1000 of person), mean \pm SD & $5813 \pm 6950$ & $4602 \pm 6017$ & $6067 \pm 7111$ & 0.0603 \\
\hline Number of birth, mean $\pm S D$ & $78237 \pm 98505$ & $56620 \pm 77033$ & $82788 \pm 101942$ & 0.0179 \\
\hline Birth weight (grams), mean \pm SD & $3277 \pm 64$ & $3314 \pm 50$ & $3269 \pm 64$ & $<0.001$ \\
\hline $\begin{array}{l}\text { Mother's education level, High school graduate or } \\
\text { higher (\%) }\end{array}$ & $81.32 \pm 7.53$ & $82.06 \pm 4.04$ & $81.17 \pm 6.94$ & 0.2224 \\
\hline Number of hospitals, mean $\pm S D$ & $97 \pm 81$ & $52 \pm 57$ & $106 \pm 82$ & $<0.001$ \\
\hline Average temperature $\left({ }^{\circ} \mathrm{F}\right)$, mean $\pm \mathrm{SD}$ & $52.46 \pm 9.36$ & $48.33 \pm 5.24$ & $53.33 \pm 9.80$ & $<0.001$ \\
\hline
\end{tabular}

*t-tests (or Wilcoxon rank-sum tests) for continuous data, $\mathrm{X}^{2}$ tests for proportions in categories.

RGGI, regional greenhouse gas initiative.

represents the RGGI effects on infant mortality, capturing the difference in the changes in NMRs and IMRs before and after the environmental policy between RGGI states and non-RGGI states.

In addition, we performed a sensitivity analysis by excluding data from the years 2008 and 2009 to eliminate any exogenous factors that could potentially reduce GHG emissions. A prior study reported that the economic recession and moderate weather in the northeastern USA during 2008 and 2009 could lower economic activity and electricity demand, which might have resulted in lower GHG emissions. ${ }^{2}$

To account for within-state serial correlation, we used state-clustered standard errors in our analyses. All analyses were conducted using STATA V.12.

\section{Patient and public involvement}

Neither patients nor public were involved in this study. Because this study used de-identified, aggregated and publicly available secondary data, informed consent and ethical approval were not required.

\section{RESULTS}

Characteristics of RGGI states and non-RGGI states are presented in table 1. Compared with non-RGGI states, RGGI states had lower total number of births, number of hospitals and average temperatures although the level of the median household income and the average birth weight in RGGI states were higher. However, no significant differences were observed between RGGI states and non-RGGI states in characteristics such as GDP, residential population, birth rate of black babies and mother's education levels. In addition, the sex ratios of newborn males to newborn females were also similar between RGGI states and non-RGGI states before RGGI implementation (1.051 and 1.050, respectively) and after RGGI implementation (1.053 and 1.049, respectively) (data not shown in table 1 ).

Figure 1 shows a trend in the observed overall NMRs and overall IMRs over time. Prior to RGGI implementation
(2003-2008), changes in overall NMRs were -0.23 $(=4.38-4.61)$ per 1000 live births and $-0.38(=4.17-4.55)$ per 1000 live births in non-RGGI states and RGGI states, respectively. Accordingly, RGGI states had a larger change in overall NMRs during 2003-2008 (difference in NMR changes between RGGI states and non-RGGI states during 2003-2008=0.15 per 1000 live births). After RGGI implementation (2009-2014), changes in overall NMRs were -0.13 per 1000 live births and -0.59 per 1000 live births in non-RGGI states and RGGI states, respectively. Therefore, we could observe a much larger decrease in overall NMRs in RGGI states compared with non-RGGI states after RGGI implementation. The difference in NMR decreases between RGGI states and non-RGGI states during 2009-2014 (0.46 per 1000 live births) was about three times higher than that before RGGI implementation (0.15 per 1000 live births). Similarly, the decrease in overall IMRs among RGGI states was larger than that among non-RGGI states after RGGI implementation.

Table 2 presents the DID estimates of the RGGI's impact on mortality outcomes. As noted earlier, an interaction term in the adjusted DID model captures the effect of RGGI on infant death rates in RGGI states compared with its effect in non-RGGI states. Our results from an adjusted DID model show that implementation of RGGI was associated with significant decreases in overall NMRs (a reduction of 0.41/1000 live births) and male NMRs (a reduction of $0.43 / 1000$ live births) in RGGI states ( $p<0.001$ and $p=0.016$, respectively). However, RGGI did not have a significant effect on female NMRs $(\mathrm{p}=0.086)$. Similarly, overall IMRs and male IMRs decreased significantly by $0.37 / 1000$ live births and $0.61 / 1000$ live births, respectively, after implementation of RGGI ( $\mathrm{p}=0.003$ and $\mathrm{p}=0.001$, respectively) while female IMRs were not significantly affected by RGGI $(p=0.068)$. The full results obtained from the DID regressions are available in online supplementary table 1 .

These findings were not substantially changed in our sensitivity analysis when data from the years 2008 and 

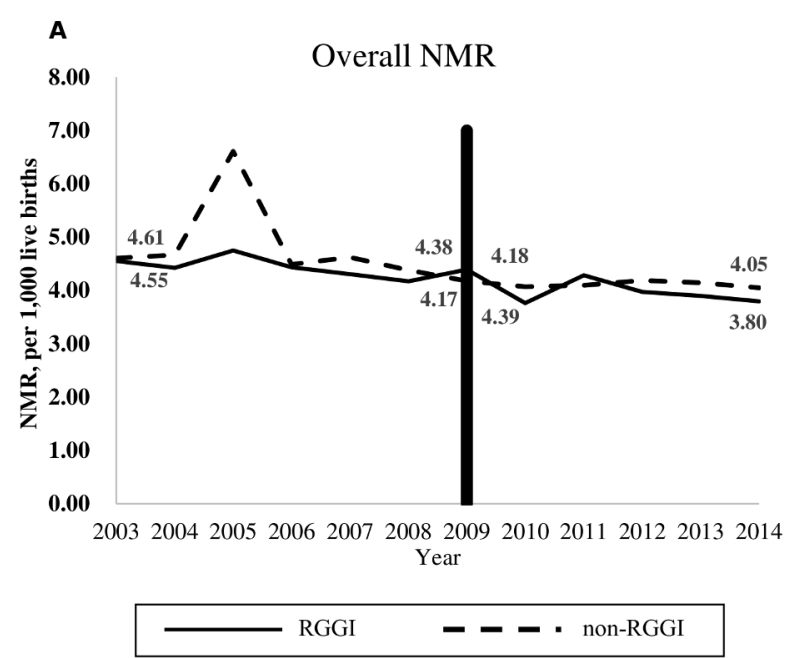

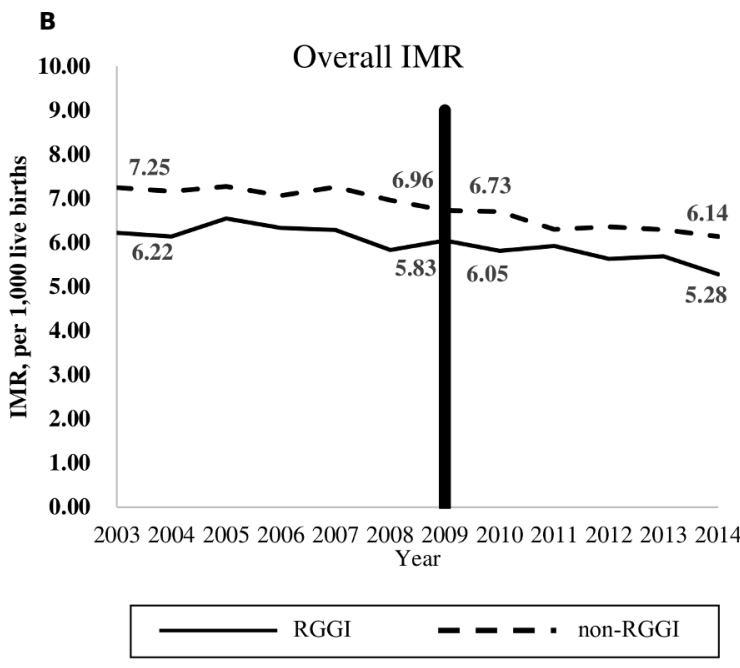

Figure 1 Observed (A) overall NMRs and (B) overall IMRs in RGGI states and non-RGGI states in the USA, 2003-2014. IMR, infant mortality rate; NMR, neonatal mortality rate; RGGI, Regional Greenhouse Gas Initiative.

2009 were excluded in the analysis (table 3 ). That is, overall NMRs and male NMRs $(0.53 / 1000$ live births and $0.62 / 1000$ live births, respectively) as well as overall IMRs and male IMRs $(0.51 / 1000$ live births and $0.85 / 1000$ live births, respectively) were significantly reduced in RGGI states after the implementation of RGGI. However, female IMRs became significant with a reduction of $0.35 / 1000$ live births in the sensitivity analysis.

After verifying significant decreases in infant mortality outcomes among RGGI states during 2009-2014, we conducted further analyses to examine the association between an air pollutant $\left(\mathrm{CO}_{2}\right)$ and infant mortality. Our results indicate that the concentration of atmospheric $\mathrm{CO}_{2}$ was positively associated with infant mortality (change in overall NMRs per unit increase in $\mathrm{CO}_{2}$ : $0.007 / 1000$ live births, $\mathrm{p}=0.016$; change in overall IMRs per unit increase in $\mathrm{CO}_{2}: 0.009 / 1000$ live births, $\mathrm{p}=0.023$, see online supplementary table 2 for full results).

\section{DISCUSSION}

RGGI, the first market-based regulatory GHG emission trading scheme (ETS) in the USA, was implemented in 2009. The objective of this study was to examine whether its implementation affected public health, particularly infant death rates, since infant mortality has been widely accepted as a proxy for public health. Our results showed that the implementation of RGGI was associated with a

\begin{tabular}{|c|c|c|c|c|}
\hline & Outcomes & & Change in rate (SE) & $P$ value \\
\hline \multirow[t]{6}{*}{ Crude* $^{*}$} & \multirow{3}{*}{$\begin{array}{l}\text { NMR, per } 1000 \text { live } \\
\text { births }\end{array}$} & Total & $-0.423(0.088)$ & $<0.001$ \\
\hline & & Males & $-0.460(0.153)$ & 0.004 \\
\hline & & Females & $-0.234(0.146)$ & 0.116 \\
\hline & \multirow[t]{3}{*}{ IMR, per 1000 live births } & Total & $-0.496(0.159)$ & 0.003 \\
\hline & & Males & $-0.797(0.231)$ & 0.001 \\
\hline & & Females & $-0.360(0.211)$ & 0.095 \\
\hline \multirow[t]{6}{*}{ Adjusted $†$} & \multirow{3}{*}{$\begin{array}{l}\text { NMR, per } 1000 \text { live } \\
\text { births }\end{array}$} & Total & $-0.405(0.091)$ & $<0.001$ \\
\hline & & Males & $-0.425(0.170)$ & 0.016 \\
\hline & & Females & $-0.215(0.123)$ & 0.086 \\
\hline & \multirow[t]{3}{*}{ IMR, per 1000 live births } & Total & $-0.370(0.118)$ & 0.003 \\
\hline & & Males & $-0.608(0.170)$ & 0.001 \\
\hline & & Females & $-0.242(0.129)$ & 0.068 \\
\hline
\end{tabular}

${ }^{*}$ Adjusted for state- and year-fixed effects only.

†Adjusted for state- and year-fixed effects, GDP, residential population, total number of births, birth weight, birth rate of black babies, mother's education level, number of hospitals, median household income and average temperature. 
Table 3 Sensitivity analysis results: R egional Greenhouse Gas Initiative impacts on morality outcomes†

Change in NMRs, per 1000 live births (SE)

Change in IMRs, per 1000 live births (SE)

\begin{tabular}{|c|c|c|c|c|c|c|}
\hline Variable & Total & Boys & Girls & Total & Boys & Girls \\
\hline GDP & $\begin{array}{c}-1.86 e-06 \\
(1.30 e-06)\end{array}$ & $\begin{array}{c}-1.91 e-06 \\
(1.34 e-06)\end{array}$ & $\begin{array}{c}-2.09 e-06 \\
(1.45 e-06)\end{array}$ & $\begin{array}{c}-3.02 e-06 \\
(1.75 e-06)\end{array}$ & $\begin{array}{c}-2.53 e-06 \\
(2.17 e-06)\end{array}$ & $\begin{array}{l}-2.71 e-06 \\
(2.05 e-06)\end{array}$ \\
\hline $\begin{array}{l}\text { Median household } \\
\text { income }\end{array}$ & $\begin{array}{l}-7.70 e-06 \\
(0.0000165)\end{array}$ & $\begin{array}{l}-1.32 e-06 \\
(0.0000188)\end{array}$ & $\begin{array}{l}-2.75 e-06 \\
(0.0000191)\end{array}$ & $\begin{array}{l}-3.42 e-06 \\
(0.0000241)\end{array}$ & $\begin{array}{l}-3.23 e-06 \\
(0.0000315)\end{array}$ & $\begin{array}{l}0.0000117 \\
(0.0000282)\end{array}$ \\
\hline Birth weight & $\begin{array}{l}-0.0081901 \\
(0.0057610)\end{array}$ & $\begin{array}{l}-0.0035003 \\
(0.0051013)\end{array}$ & $\begin{array}{l}-0.0133304 \\
(0.0076550)\end{array}$ & $\begin{array}{l}-0.0125448 \\
(0.0089260)\end{array}$ & $\begin{array}{l}-0.0109829 \\
(0.0100007)\end{array}$ & $\begin{array}{l}-0.0195128 \\
(0.0123177)\end{array}$ \\
\hline Birth rate of black babies & $\begin{array}{l}0.0112633 \\
(0.0285210)\end{array}$ & $\begin{array}{l}0.0027859 \\
(0.0447368)\end{array}$ & $\begin{array}{l}0.0045914 \\
(0.0385191)\end{array}$ & $\begin{array}{l}0.0804308^{\star} \\
(0.0368247)^{\star}\end{array}$ & $\begin{array}{l}0.1073290 \\
(0.0645677)\end{array}$ & $\begin{array}{l}0.1170497^{\star *} \\
(0.0333728)^{\star \star}\end{array}$ \\
\hline Average temperature & $\begin{array}{l}0.0117115 \\
(0.0197077)\end{array}$ & $\begin{array}{l}0.0215859 \\
(0.0255102)\end{array}$ & $\begin{array}{l}0.0125384 \\
(0.0238854)\end{array}$ & $\begin{array}{l}0.0327286 \\
(0.0289116)\end{array}$ & $\begin{array}{l}0.0485751 \\
(0.0372411)\end{array}$ & $\begin{array}{l}0.0625248 \\
(0.0396741)\end{array}$ \\
\hline Interaction term $\ddagger$ & $\begin{array}{l}-0.5326649^{\star \star \star} \\
(0.1075000)^{\star \star \star}\end{array}$ & $\begin{array}{l}-0.6170827^{\star \star \star} \\
(0.1519119)^{\star \star \star}\end{array}$ & $\begin{array}{l}-0.2684320 \\
(0.1350443)\end{array}$ & $\begin{array}{l}-0.5085975^{\star \star} \\
(0.1583920)^{\star \star}\end{array}$ & $\begin{array}{l}-0.8462957^{\star \star \star} \\
(0.1865184)^{\star \star \star}\end{array}$ & $\begin{array}{l}-0.3538008^{*} \\
(0.1506759)^{\star}\end{array}$ \\
\hline
\end{tabular}

${ }^{*} \mathrm{p}<0.05,{ }^{* *} \mathrm{p}<0.01,{ }^{* * *} \mathrm{p}<0.001$.

†Excluding data from the years 2008 and 2009.

¥This interaction term between RGGI status and time captures the impacts of RGGI on mortality outcomes.

IMRs, infant mortality rates; NMRs, neonatal mortality rates; RGGI, regional greenhouse gas initiative.

reduction in overall neonatal deaths and overall infant deaths. This could be explained by fuel switching trends observed in RGGI states. Previous studies have reported that RGGI implementation has encouraged fuel switching from coal to clean natural gas in electricity generation in the USA. ${ }^{2}{ }^{28}$ Fossil fuels such as coal and petroleum are high-carbon intensity sources which emit two times or more $\mathrm{CO}_{2}$ than does natural gas. As such, total $\mathrm{CO}_{2}$ emissions from power plants in RGGI states have dropped substantially. A decrease in air pollutant $\left(\mathrm{CO}_{2}\right)$ concentrations in RGGI states might be associated with the reduced overall infant death rates in these states. Associations of air pollution with risk of premature mortality have been evidenced in a number of studies. ${ }^{781011}$ Similarly, our further analyses also showed that overall NMRs and IMRs increased as the $\mathrm{CO}_{2}$ level increased. Air pollution's adverse effects on fetal development were suggested by Chay and Greenstone as a mechanism through which air pollution affects infant mortality. ${ }^{13} 14$

Another finding of this study was the differences in the impact of RGGI on the infant health of males and females. That is, male NMRs and male IMRs were significantly reduced after the implementation of RGGI while this environmental policy did not significantly affect deaths in female infants. This finding aligns with the traffic-related air pollution on childhood asthma (TRAPCA) study reporting different health responses in boys and girls aged $0-2$ years to air pollution. ${ }^{29}$ The TRAPCA study showed stronger associations between air pollutants and non-specific respiratory symptoms (eg, cough without infection, nocturnal dry cough) among males than among females. ${ }^{29}$ Greater susceptibility to diseases and higher mortality among boys are used to explain by the differences in genetic and biological makeup between boys and girls. Female infants are known to have larger airways relative to body size ${ }^{30}$ and their specific airway resistance is lower than in male infants. ${ }^{31}$ However, studies of older children and adults often suggest stronger effects of air pollution among females. For older-aged children and adults, not only biological sex differences but also other social gender differences come into play in modifying the effects of air pollution. In general, social gender can affect the presence of exposures (eg, exposure from using cosmetics or jewellery), the intensity of exposures (eg, frequency of cooking) and coexposures (eg, diet or smoking). These social gender differences can change over the life course and do not exhibit predictable patterns. Therefore, these social gender differences aggregated with biological sex differences make gender effects more complicated, which might have led to large variations in the findings among prior studies for olderaged children and adults. ${ }^{21}$ Regarding infants in this study and the TRAPCA study, observed modification was most likely attributable to biological sex differences. In other 
words, social gender differences were less likely to serve as an effect modifier in these two studies.

The impacts of implementation of RGGI on infant death rates were not changed substantially when the timeframe was varied in our sensitivity analysis. We excluded data from the years 2008 and 2009 in our sensitivity analysis to isolate the impact of RGGI on infant deaths while eliminating the effects of the economic recession and the moderate weather experienced during this time period. As noted earlier, the economic recession and moderate weather could have led to a reduction in GHG emissions, thereby affecting infant mortality. Findings in the sensitivity analyses still indicated a linkage between RGGI and infant mortality reduction (eg, total NMRs and male NMRs as well as total IMRs and male IMRs). Notably, female IMRs also reduced after the RGGI implementation although its impacts on female IMRs were much smaller than those on male IMRs.

To the best of our knowledge, this study represents the first attempt to examine infant health effects associated with a specific US environmental regulation, RGGI. In particular, we examined the RGGI effects on infant health stratified by sex. Our study findings have important implications for environmental and public health policy. According to the WHO, one out of every nine deaths at all ages directly resulted from air pollution in 2012, indicating air pollution as a large environmental health risk. ${ }^{32}$ The annual global cost of healthcare related to pollution was estimated to be between $\$ 240$ billion and $\$ 630$ billion. $^{33}$ To cope with air pollution problems, the European Union implemented the European Union (EU) ETS in 2005, which is the world's first cap-and-trade programme. Benefits of this programme have emerged yielding significant reductions in GHG emissions in the EU. ${ }^{34}$ Similarly, our findings show the beneficial effects of the USA's cap-and-trade programme to limit $\mathrm{CO}_{2}$ emissions, which informs policymakers of the tangible public health benefits of RGGI. RGGI's experiences can encourage non-RGGI states to enhance their efforts to reduce $\mathrm{CO}_{2}$ emissions or participate in the RGGI programme, thereby broadening the RGGI market. This could lead to air quality improvements in more states, which can significantly benefit infant health. Alternatively, RGGI could be viewed as potential federal legislation.

Several limitations warrant discussion. First, an assumption behind the DID approach is that without the implementation of RGGI, the non-RGGI states would have experienced a similar trend in infant deaths to the RGGI states (parallel trend assumption). However, this assumption could be violated if there is any unobserved policy change affecting infant health in non-RGGI states only. A violation of the parallel trend assumption would make our estimates biased. As such, we performed a test to check whether this assumption was met. Our test results of the pre-RGGI period showed no significantly different trends in infant mortality between RGGI states and non-RGGI states. While this trend might not persist in the post-RGGI period, it suggests that any bias from the violation of this assumption is likely to be small. Second, RGGI states have entered a second phase in which the existing cap level has been reduced to match their actual $\mathrm{CO}_{2}$ emissions levels since 2014. Accordingly, the emission cap declines 2.5 percent each year between 2015 and 2020 in this new phase. Therefore, it is uncertain how differently the adjusted (reduced) emissions cap will impact infant mortality than the original emissions cap. A future follow-up study extending the timeframe may elucidate this point. Likewise, our study findings may not be generalizable to a GHG reduction policy outside the USA. Moreover, infant deaths in this study were all-cause mortality rather than disease-specific mortality. Accordingly, our analyses were not granular enough to capture the reasons for deaths. Condition-specific mortality would provide information on which fetal organ systems are most affected by air pollution. However, despite this limitation, our study shows the comprehensive health effects in infants associated with air pollution. Finally, residual confounding by unmeasured factors might be possible, which is the limitation inherent in any observational studies. The study findings could be biased to the extent unmeasured confounders affect the association of RGGI implementation with infant mortality.

In conclusion, the RGGI programme started as a means to limit $\mathrm{CO}_{2}$ emissions in January 2009 in the USA. Although this programme was originally designed to spur innovation in the clean energy economy, it also conferred significant benefits to infant health. Our study found that RGGI was associated with decreases in infant mortality. This finding would be informative to policymakers. Future environmental and public health policy can be implemented toward expanding the benefits of RGGI.

Contributors $\mathrm{JL}$ analysed the data. Both JL and TP conceptualised and designed the study, interpreted the results, and drafted and revised the article.

Funding The authors have not declared a specific grant for this research from any funding agency in the public, commercial or not-for-profit sectors.

Competing interests None declared.

Patient consent for publication Not required.

Ethics approval Institutional review board approval was not required because this study used de-identified, aggregated and publicly available secondary data.

Provenance and peer review Not commissioned; externally peer reviewed. Data sharing statement № additional data available.

Open access This is an open access article distributed in accordance with the Creative Commons Attribution Non Commercial (CC BY-NC 4.0) license, which permits others to distribute, remix, adapt, build upon this work non-commercially, and license their derivative works on different terms, provided the original work is properly cited, appropriate credit is given, any changes made indicated, and the use is non-commercial. See: http://creativecommons.org/licenses/by-nc/4.0/.

\section{REFERENCES}

1. LeGrand M. The regional greenhouse gas Initiative: winners and losers. Columbia Journal of Environmental Law 2013;24:29-35.

2. Murray BC, Maniloff PT. Why have greenhouse emissions in RGGI states declined? An econometric attribution to economic, energy market, and policy factors. Energy Economics 2015;51:581-9. 
3. Kim M-K, Kim T. Estimating impact of regional greenhouse gas initiative on coal to gas switching using synthetic control methods. Energy Economics 2016;59:328-35.

4. Remsuer JL. The regional greenhouse gas initiative: lessons learned and issues for congress. Washington, DC: Congressional Research Service, 2017.

5. Delfino RJ, Wu J, Tjoa T, et al. Asthma morbidity and ambient air pollution: effect modification by residential traffic-related air pollution. Epidemiology 2014;25:48-57.

6. Breysse PN, Diette GB, Matsui EC, et al. Indoor air pollution and asthma in children. Proc Am Thorac Soc 2010;7:102-6.

7. Allen RW, Gombojav E, Barkhasragchaa B, et al. An assessment of air pollution and its attributable mortality in Ulaanbaatar, Mongolia. Air Qual Atmos Health 2013;6:137-50.

8. Chen $\mathrm{R}$, Kan $\mathrm{H}$, Chen $\mathrm{B}$, et al. Association of particulate air pollution with daily mortality: the China Air Pollution and Health Effects Study. Am J Epidemiol 2012;175:1173-81.

9. Greenstone M, Hanna R. Environmental regulations, air and water pollution, and infant mortality in India. Am Econ Rev 2014;104:3038-72

10. Luechinger S. Air pollution and infant mortality: a natural experiment from power plant desulfurization. $J$ Health Econ 2014;37:219-31.

11. Tanaka S. Environmental regulations on air pollution in China and their impact on infant mortality. J Health Econ 2015;42:90-103.

12. Currie $J$, Neidell M. Air pollution and infant health: what can we learn from California's recent experience? Q J Econ 2005;120:1003-30.

13. Chay KY, Greenstone M. Air Quality, Infant Mortality, and the Clean Air Act of 1970. Cambridge, MA: National Bureau of Economic Research, 2003. NBER Working Paper 10053.

14. Chay KY, Greenstone M. The impact of air pollution on infant mortality: Evidence from geographic variation in pollution shocks induced by a recession. Q J Econ 2003;118:1121-67.

15. Fly-Johnson YW, Levine R, Rowlwy D, et al. United States black:white infant mortality disparities are not inevitable: identification of community resilience independent of socioeconomic status. Ethn Dis 2010;20:131-5.

16. Rossen LM, Khan D, Schoendorf KC. Mapping geographic variation in infant mortality and related black-white disparities in the US. Epidemiology 2016;27:690-6.

17. Brown Speights JS, Goldfarb SS, Wells BA, et al. State-level progress in reducing the black-white infant mortality gap, United States, 1999-2013. Am J Public Health 2017;107:775-82.

18. Komro KA, Livingston MD, Markowitz S, et al. THe effect of an increased minimum wage on infant mortality and birth weight. Am J Public Health 2016;106:1514-6.

19. Bhatt $\mathrm{CB}$, Beck-Sagué $\mathrm{CM}$. Medicaid expansion and infant mortality in the United States. Am J Public Health 2018;108:565-7.
20. Kan H, London SJ, Chen G, et al. Season, sex, age, and education as modifiers of the effects of outdoor air pollution on daily mortality in shanghai, china: The public health and air pollution in Asia (PAPA) Study. Environ Health Perspect 2008;116:1183-8.

21. Clougherty JE. A growing role for gender analysis in air pollution epidemiology. Environ Health Perspect 2010;118:167-76.

22. Oiamo TH, Luginaah IN. Extricating sex and gender in air pollution research: a community-based study on cardinal symptoms of exposure. Int J Environ Res Public Health 2013;10:3801-17.

23. U.S. Centers for Disease Control and Prevention. Infant death, 20032014. https://wonder.cdc.gov/ (Accessed 11 May 2018).

24. Federal Reserve bank of St. Louis Economic Data (FRED). Total Gross Domestic Product, Resident population, Median household income, 2003-2014. https://fred.stlouisfed.org/ (Accessed 21 Dec 2018).

25. U.S. Centers for disease control and prevention. Natality information, 2003-2014. https://wonder.cdc.gov/ (Accessed 11 May 2018)

26. Kaiser Family Foundation. The number of hospitals in each state. https://www.kff.org/ (Accessed 20 Nov 2017).

27. National Oceanic and Atmospheric Administration. National Weather Service - National Climate. https://www.ncdc.noaa.gov/ (Accessed 21 Dec 2018).

28. Tietenberg TH. Reflections--carbon pricing in practice. Review of Environmental Economics and Policy 2013;7:313-29.

29. Gehring U, Cyrys J, Sedlmeir G, et al. Traffic-related air pollution and respiratory health during the first 2 yrs of life. Eur Respir $J$ 2002;19:690-8

30. Thurlbeck WM. Postnatal human lung growth. Thorax 1982;37:564-71.

31. Doershuk CF, Fisher BJ, Matthews LW. Specific airway resistance from the perinatal period into adulthood. Alterations in childhood pulmonary disease. Am Rev Respir Dis 1974;109:452-7.

32. World Health Organization. Ambient air pollution: a global assessment of exposure and burden of disease. 2016. http://apps. who.int/iris/bitstream/handle/10665/250141/9789241511353eng.pdf;jsessionid=83B8656493745BA495BA2223515FB843? sequence $=1$ (Accessed 22 Apr 2018).

33. Preker AS, Adeyi OO, Lapetra MG, et al. Health care expenditures associated with pollution: exploratory methods and findings. Ann Glob Health 2016;82:711-21.

34. Considine T, Larson DF. Short term electric production technology switching under carbon cap and trade. Energies 2012;5:4165-85.

35. Delarue E, Voorspools K, D'haeseleer W. Fuel Switching in the Electricity Sector under the EU ETS: Review and Prospective. $J$ Energ Eng 2008;134:40-6. 